\title{
Rodrigo Carazo Odio: sus reflexiones sobre política, Estado y empresa pública
}

Recibido: 10 de septiembre 2016

Revisado: 24 de octubre 2016

Aprobado: 4 de noviembre 2016

José Daniel Rodríguez

Arrieta

Costarricense. Licenciado en

Ciencias Políticas por la

Universidad de Costa Rica y

docente de la Escuela de

Ciencias Políticas e

investigador del Centro de

Investigación y Estudios

Políticos (CIEP) de esta misma universidad. Además coordina la Cátedra Rodrigo

Carazo Odio

Correo electrónico:

josedanielcr@gmail.com

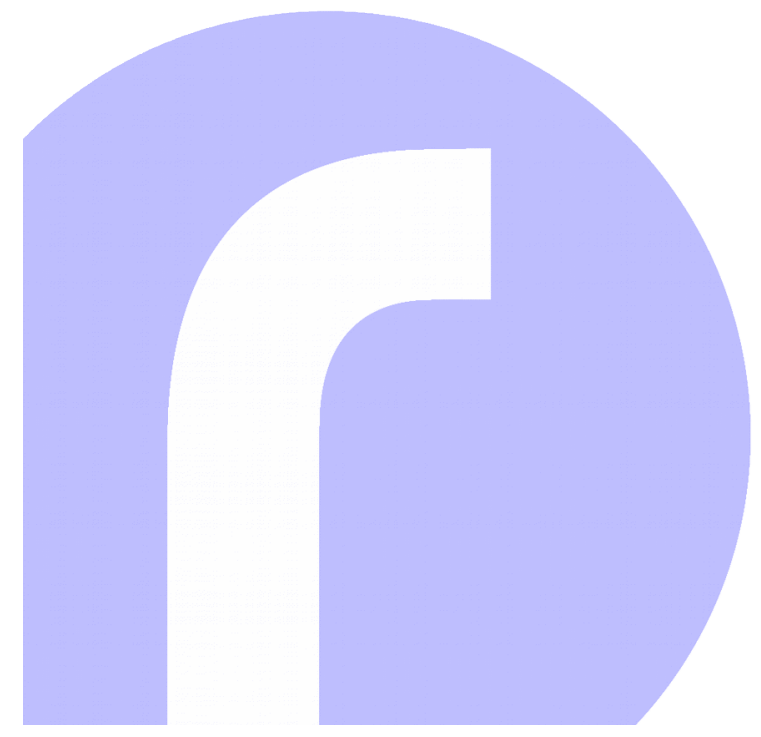

Resumen: Este artículo pretende resaltar las principales ideas del expresidente de la República de Costa Rica, Rodrigo Carazo, acerca de la política, el Estado y la empresa pública. A partir de un estudio e interpretación de su obra, se espera caracterizar estos conceptos de su óptica y con ello aportar elementos que expliquen sus decisiones. Rodrigo Carazo vio en la política un medio en función de la sociedad que, al igual que el Estado, debía ser garante de una distribución justa de los recursos mientras que la empresa pública es crucial en el desarrollo.

Palabras clave: Estado; empresa pública; pensamiento político; Rodrigo Carazo.

\section{Rodrigo Carazo Odio: His Ideas about Politics, State and Public Companies}

Abstract: This article aims to highlight the main ideas of Rodrigo Carazo, former President of the Republic of Costa Rica, concerning politics, the State and public companies. Through the study and interpretation of his work, the article sets out to characterize these concepts from Carazo's perspective, and thus provide elements to understand some of his decisions. Rodrigo Carazo saw politics as a means to benefit society, which, like the State, must guarantee the fair distribution of resources, while public companies are crucial for development.

Key words: State; public company; political thought; Rodrigo Carazo. 


\section{Presentación}

Este artículo se desprende de una investigación apoyada por la Escuela de Ciencias Políticas de la Universidad de Costa Rica y el Centro de Investigación y Estudios Políticos (CIEP), denominada "El Estado y la empresa pública en el pensamiento de Rodrigo Carazo Odio".
El presente artículo rescata la obra de Rodrigo Carazo Odio mediante tres conceptos importantes: política, Estado y empresa pública. Se considera que la interpretación de estos, por parte de Carazo, definió su accionar al frente del Poder Ejecutivo de Costa Rica entre 1978 y 1982. Su reflexión se derivó de un proceso de maduración como resultado de su experiencia en la política nacional desde muy joven y siempre estuvo presente en sus discursos y praxis desde el momento de dejar la silla presidencial hasta el día de su fallecimiento en el año 2009.

Mediante el estudio de su obra, puede entenderse su reflexión acerca de qué es -y debe ser la política- en tanto un medio y nunca un fin en sí mismo. Igualmente, Rodrigo Carazo pensó el Estado como el garante de la distribución equitativa de los recursos y en su solidez identificó las bases de la democracia costarricense. Finalmente, la empresa pública garantizaría un desarrollo tenaz y ambicioso de una sociedad que, de acuerdo con Carazo Odio, ve en estas instituciones la fundamentación de su identidad misma.

\section{Rodrigo Carazo y el pensamiento político costarricense}

El repaso y la recuperación del acervo de conocimiento nacional es una labor ineludible en la constante construcción y deconstrucción de la sociedad, sus bases y fundamentaciones. Esto no debe plantear mayor duda.

Por ello, se debe reconocer la relevancia del estudio del pensamiento político de los actores significativos en el devenir de Costa Rica, pues, entre otras cosas, los pueblos "han forjado ideas, doctrinas muchas veces venidas de fuera, pero asumidas dentro de una circunstancia muy particular que le da un sentido propio y específico a esa concepción universal" (Mora 1993, 14).

Una de las áreas en la cual se evidencia un vacío en la recuperación de la reflexión política y filosófica en el país es sobre el Estado; en particular, sobre el origen, la evolución y la transformación de la institucionalidad costarricense, así como la empresa pública. Cabe comprender que este no es un tema accesorio, porque las instituciones y las empresas públicas han jugado un papel clave en el desarrollo nacional y han sido fundamentales en la expansión sectorial y territorial de servicios públicos, al tiempo de servir como generador de movilidad social. 
Para entender la evolución de la empresa pública costarricense en particular, y el Estado en general, es menester analizar el pensamiento político de quienes impulsaron y gestionaron dicha institucionalidad. Por tanto, una de las fuentes importantes, de estudio obligatorio, y que debe abordarse a profundidad, es la reflexión y acción de quienes han ejercido la primera magistratura de la República como un actor usualmente determinante. Mora $(1993,14)$ lo explica sucintamente: "el desarrollo del pensamiento es directamente proporcional a la conciencia de sí que van adquiriendo los pueblos".

Sobre esta línea, se justifica el abordaje del pensamiento de Rodrigo Carazo Odio con respecto al Estado y la empresa pública y su visión política detrás de ello. La particular coyuntura de su mandato es una razón en sí, debido a la significancia del momento en un ámbito de crisis, paralelo al auge de un modelo político-económico hegemónico, actualmente vigente y consolidado.

Rodrigo Carazo fue un político descendiente de las instituciones de un Estado gestor; es decir, del Estado resultante de la llamada "Segunda República" costarricense y del cual, posiblemente, pudo haber sido el último mandatario. Esto reflejaría la dinámica social y política de un actor formado en las bases de una naciente práctica ideológica. Se comprenderá, entonces, con más claridad cómo el pensamiento y la reflexión de Rodrigo Carazo no es posible de estudiar sin una articulación con su obra empírica y su visión de estadista y el contexto vivido.

La reflexión de Rodrigo Carazo sobre la razón y función del Estado costarricense y su articulación social mediante las instituciones públicas se encuentra esparcida, en primer lugar, a lo largo de una obra propia a partir de su primer libro en el año 1955.

A partir de ese momento, el pensamiento de don Rodrigo sobre la cosa pública inicia una articulación y un proceso de maduración. Cabe apuntar que un segmento esencial de dicha reflexión política se encuentra en documentos mucho menos sistematizados y estudiados que sus libros. Como parte de dicho acervo, puede encontrarse una considerable cantidad de artículos académicos, discursos, entrevistas y comunicados emitidos, publicados o realizados tanto antes de ser presidente de la República, durante el tiempo que ejerció la primera magistratura y en los años posteriores, lo cual de hecho es necesario resaltar, porque ello evidenció el interés constante de don Rodrigo Carazo por los asuntos del país independientemente de su posición de turno.

\section{Rodrigo Carazo y la política como medio para un fin}

Desde célebres escritos y reflexiones como en El Príncipe, del florentino Machiavelli o de Gaetano Mosca acerca de La clase política, hace más de un siglo, mucho se ha desarrollado alrededor de este segmento de la sociedad que tiene una relación directa con el poder, su ejercicio y conservación. Más 
importante todavía es el estudio del político y del que hace política en tanto su desempeño e influencia sobre la dirección de la res publica, lo cual tendrá un efecto en el camino por seguir.

El politólogo estadounidense Robert Dahl $(1968,111)$ afirmó que "la acción política, al igual que otras acciones humanas consiste en tomar decisiones en escoger de alguna forma entre posibles alternativas y luego tratar de realizar o hacer efectiva la elección que se ha tomado", y ello implica normalmente una evaluación de consecuencias y justificaciones de esas elecciones, lo cual expondría al político en sus virtudes y carencias, ejercido esto mayormente desde la polisémica arena que es el Estado.

A lo largo de su obra y otras intervenciones, Rodrigo Carazo fue explícito, y otras veces sugerente, de las cualidades que consideraba que los detentores del poder, y los mismos funcionarios integrados al aparato público -con una cuota de poder en todo caso- debían tener, desarrollar y siempre aspirar para ejercer su trabajo con responsabilidad y con base en valores y principios no negociables; de hecho, las exigencias de Carazo frente a esas virtudes, que consideró como mínimas, de los políticos le llevó a separarse de grupos y organizaciones políticas nacionales por considerar que tales valores y principios habían sido trastocados y, consecuentemente, afectaban en mayor o menor grado los intereses del colectivo y de lo que él constantemente en sus obras llamó el Bien Común.

El periodista Enrique Benavides $(1975,39)$ concluye que para Rodrigo Carazo el principal problema político de la organización social pública pasa, en un primer momento, por la persona antes que la estructura institucional. Esta persona puede ser el Presidente, el diputado, el ministro o cualquier otro funcionario público. En este sentido, se entiende que la persona, en todos los niveles de acción y decisión, finalmente define la dirección de las instituciones y así, por consecuencia, las instituciones son lo que hacen de ellas. Lo apunta claramente Carazo al afirmar: "Claro que muchas empresas públicas podrían caminar mejor, ser más eficientes, cumplir muy bien sus objetivos. Claro, también que muchas empresas privadas podrían caminar mejor. Todo depende de la gente y su actitud" $(1993,16)$.

Asimismo, desde la óptica caracista, esta reflexión se extiende a toda actividad colectiva, desde asociaciones (públicas o privadas) hasta partidos políticos. En este último caso, es el conjunto el que refleja fielmente las actitudes de sus integrantes. En cuanto a los partidos políticos, Carazo sentencia que, en el caso de los políticos corrompidos, utilizan su plataforma y "la despreocupación del costarricense por todo aquello que no toca sus intereses personales o del grupo" $(1975,39)$ para actuar según convenga a su beneficio propio.

Así, para Rodrigo Carazo, los entes políticos son la suma de las personalidades, capacidades y limitaciones de las personas que ejercen la política. Esto es extensible a los que ejercen la función pública, lo cual define un elemento nuclear en la constitución y la evaluación de la empresa pública de acuerdo con su criterio. Valga destacar un párrafo de las Bases del 
Programa de Gobierno de la Coalición Unidad $(1977,7)$, del cual fue su candidato:

Considerando la función pública, no como una prerrogativa personal que se desempeña en beneficio propio, sino como un mandato que encarna la voluntad de la ciudadanía y como tal debe ser respetado por constituir un gesto de confianza que el pueblo deposita en el gobernante.

Asimismo, cabe resaltar en este mismo documento, que como parte de lo que denomina "Medios globales de acción", el partido impulsado por Rodrigo Carazo reiteró como un principio de su gobierno

Velar por el cumplimiento de la función pública con el más estricto sentido de honestidad, a base de ejemplo y disciplina, para que el Estado deje de ser considerado como un medio de beneficio personal y se convierta en un instrumento de progreso a favor de la comunidad $(1977,15)$.

A lo largo de su vida pública, Rodrigo Carazo vuelve reiteradamente sobre la caracterización de la clase política, así como sus acciones y de qué forma esto tuvo una influencia directa en las decisiones que tomó personalmente y con base en sus convicciones. El hecho que marcó de manera definitiva su carrera política fue haber abandonado las tiendas del Partido Liberación Nacional (PLN), agrupación en la cual se abrió un espacio y con el cual inició su ejercicio de la función pública. Igualmente, acciones y posiciones de otros actores a lo interno del partido lo hicieron dejar esas tiendas políticas; en el año 1975, Rodrigo Carazo lo resumió a Enrique Benavides: ${ }^{1}$

El Partido Liberación Nacional está minado profundamente por una crisis de corrupción, de obediencia y sometimiento de sus dirigentes a su líder máximo que es el que manda dentro y fuera del partido y 1. Para una referencia más detallada, en su obra autobiográfica, Carazo Tiempo y Marcha (1989), Rodrigo Carazo desarrolla exhaustiva y cronológicamente los distintos hechos que vivió fuera y dentro del Partido Liberación Nacional y que culminaron con su dimisión. una perpetuación suya en el poder llevaría al país a un caos económico, político y moral como ya lo está llevando sin lograr aun ese objetivo. Esa descomposición 
progresiva fue precisamente la que al cabo me condujo a separarme del partido $(1975,46)$.

En el fragmento supra citado, Rodrigo Carazo achaca su dimisión del PLN a dos situaciones correlacionadas y que, a su vez, evidencian una posición acerca de aquel que ejerce la política: por un lado a la perpetuación de una misma persona en el ejercicio del poder -y con ello efectivamente también brinda una confirmación de su consecuente posición acerca de los totalitarismos- $y$, por otro lado, la corrupción como el evidente beneficio personal de los políticos que Rodrigo Carazo critica; de hecho, como él mismo lo relata en diversas fuentes, para el caso particular, la dominación ejercida por el fundador y líder histórico del partido -José Figueres Ferrerconllevó a que se cometieran actos de corrupción dentro del mismo Liberación Nacional en función de su permanencia como el candidato a la presidencia para 1970 en desmedro de una oposición en la cual figuraba Carazo Odio.

La posición de Rodrigo Carazo, referida en varias de las obras bibliográficas y periodísticas de su autoría y escritas sobre su figura, alrededor de la corrupción como la más deformada y perniciosa forma de la política y el acto más desdeñable del político, es implacable y no admite justificación. Carazo vio en la corrupción, indistintamente del nivel o la profundidad, una perversión con una consecuencia directa en el espacio público, el Bien Común y en la calidad de la democracia misma, al tiempo que se da una afectación a la ciudadanía en general y una consecuente pérdida de credibilidad en la esfera política.

Precisamente, a propósito de la declaración de guerra del Presidente Rafael Ángel Calderón a Alemania en 1941, Carazo escribió: "Un gobernante sin escrúpulos considera mejor recibir ayuda económica que defender la moral y mantener la dignidad y los valores del pueblo y de la nación costarricense" $(1989,23)$. Cabe entonces observar que, para Rodrigo Carazo, cualquier acción política -aunque fuese legal- que pusiera en peligro la soberanía nacional es en sí un acto de corrupción y este es un punto remarcable de su pensamiento, porque puede afirmarse que la corrupción en Carazo va más allá de hacer un uso indebido de recursos en beneficio propio sino que faltar gravemente a la responsabilidad depositada en la clase política es también un acto corrupto.

Consecuentemente, esta crítica de la corrupción planteó que Rodrigo Carazo tomase acciones concretas relativas a la denuncia pública de este tipo de actos. El historiador Carlos Abarca $(1995,32)$, a propósito de acciones tomadas por Rodrigo Carazo, recordó que

en la campaña de 1966 denunció el uso individual por parte del candidato Daniel Oduber de los fondos de particulares destinados al financiamiento de las 
elecciones. Para el proceso electoral de 1970, divulgó el aporte del capital extranjero a los partidos, concretamente de la Allied Chemical.

En la reflexión caracista el político es, ante todo, un servidor público en todo el sentido de la palabra. Es una persona seleccionada -sea por el pueblo o por otros funcionarios- para cumplir un rol temporal en el aparato público en función del Bien Común. El Estado es una herramienta para la consecución de este bienestar y el político es el potenciador de ello.

Precisamente, en el mensaje de toma de posesión del 8 de mayo de 1978, Rodrigo Carazo afirmó que la política "debe ser la más noble de las acciones del hombre y nunca un instrumento de beneficio personal o de grupo, y que la democracia formal debe complementarse con la democracia de participación, que ha de ser permanente" $(1978,7)$. En este acercamiento a su propia concepción de política, Rodrigo Carazo confirmó el ejercicio de esta como un acto en beneficio colectivo, nunca personal, al tiempo que extiende la función de hacer política al ciudadano en tanto la consolidación de una democracia participativa, es decir, superar lo que Weber $(2012,92)$ denominó "políticos ocasionales": "lo somos todos nosotros cuando depositamos nuestro voto, aplaudimos o protestamos en una reunión política".

Puede asegurarse que para Rodrigo Carazo, la política es un ejercicio noble pero cargado de una gran responsabilidad; es ciertamente "temporal" en el sentido de no ser o pertenecer de forma inherente a ninguna persona en particular. Es un poder designado el cual debe ser siempre dignificado por la los políticos y debe ser sujeto de rendición de cuentas.

\section{El Estado como base de la democracia real}

La forma en que Rodrigo Carazo entendió el Estado -y la empresa públicase puede identificar cuando se abordan varios ejes claves que describen e interpretan estos conceptos desde la reflexión y la praxis. De hecho, se observó que el entendimiento y la interpretación de Rodrigo Carazo acerca del Estado se caracterizó por una profundización relacionada directamente con el paso del tiempo y las distintas coyunturas que vivió.

Rodrigo Carazo vivió el inicio de su vida política en una Costa Rica dominada por viejas estructuras descendientes de una histórica, pero desgastada oligarquía cafetalera, y una antigua concepción liberal que veía al Estado como la herramienta política para la consolidación de sus proyectos propios y con una injerencia restringida en la vida social del país. También, observó los primeros movimientos populares en la reivindicación de los derechos de los trabajadores en la década de 1930 con un reflejo en la consolidación de las garantías sociales y laborales. 
2. Recuérdese que este partido surge de la fusión del partido Acción Demócrata, fundado por José Figueres, y el Centro para el Estudio de los Problemas Nacionales.

3. Este interés parte de su época como estudiante universitario; defendió su tesis de Licenciatura en Economía en la Escuela de Ciencias Económicas y Sociales de la Universidad de Costa Rica en 1955 con el tema titulado: "El problema de la vivienda en Costa Rica".
Rodrigo Carazo se inscribió, desde sus primeros pasos políticos, en una ideología socialdemócrata y particularmente trabajó en la consolidación del Partido Social Demócrata ${ }^{2}$ con una fuerte influencia de los académicos Carlos Monge Alfaro y Rodrigo Facio Brenes, de los cuales él mismo afirmó que aprendió y con los cuales coincidía en su pensamiento político (Carazo, 1989). Sobre ello, cabe afirmar que Carazo se identificaba con la posición del Centro para el Estudio de los Problemas Nacionales (CEPN) en dos aspectos que aquí interesan: con la consolidación de la democracia y la búsqueda de la justicia social (Rodríguez 1995, 25), y con un Estado que intervenga científicamente, como el organizador y el promotor general del nuevo modelo (Rovira 2000, 42-44).

Carazo Odio afirma categóricamente en Tiempo y Marcha su militancia e identificación con el Partido Social Demócrata y los postulados de este -valga recordar, muy influenciados por el pensamiento del mencionado Rodrigo Facio- que tenían por objetivo cambiar el modelo de desarrollo imperante en la Costa Rica de los años 1940, independientemente de haber sido electo como regidor de Puntarenas por el Partido Unión Nacional.

Una vez consolidado el proyecto guiado por la Junta Fundadora de la Segunda República, Rodrigo Carazo, miembro del recién fundado PLN como el resultado político de los vencedores del golpe de Estado de 1948, formó parte de este proyecto partidario que implicaría el espacio político-ideológico que buscaría la consolidación del modelo que planteó el norte del nuevo grupo en el poder.

Defendió el naciente Estado Benefactor, como el resultado del conflicto, y sostuvo los postulados socialdemócratas del PLN alrededor del nuevo modelo de desarrollo y un sistema económico que "no debe ser ni capitalista ni socialista, sino que debe buscar un punto medio" (Bodenheimer 1984, 14). Así, de acuerdo con la carta fundamental del partido: "Aquellas formas de propiedad que deben reservarse al Estado son las que tienen un poder de dominio tan grande que no pueden dejarse en manos privadas sin ser un peligro" $(1984,15)$.

Como una síntesis parcial, Rodrigo Carazo creyó indiscutiblemente en un Estado social como el que surge en respuesta a un Estado liberal tradicional que no pudo o no se interesó en una mejora en la situación de los sectores más vulnerables. En este aspecto, Rodrigo Carazo mostró, en un contexto preguerra, su admiración ante las reformas sociales de la década de 1940, lo cual tildó como "un avance en el desarrollo social en beneficio de todos los costarricenses" $(1989,24)$.

Un aspecto, que se refuerza con esta concepción del Estado social en Rodrigo Carazo, deviene de su interés particular en el tema de la vivienda de interés social. ${ }^{3}$ Entre otras fuentes, en Administración de vivienda (1968) publicado en Venezuela, Carazo desarrolló toda una tesis sobre el tema, que, apartando la materia técnica, aborda el asunto como una importante labor que se cumple desde el Estado con la salvedad de que no debe permitirse un 
permanente paternalismo. Este constituía un rasgo del Estado en el cual creía Rodrigo Carazo.

Ante este aspecto fue enfático: "un sistema político paternalista contribuye a fortalecer los sentimientos de dependencia y de vagancia, en tal forma que las personas y la comunidad se acostumbran a esperar las soluciones promovidas por los jerarcas" (1995, 17A); de hecho, en 1977 Carazo afirmó a Enrique Benavides

El paternalismo y esa actitud nacional de esperar la solución de los problemas sin esfuerzo propio, son dos caras de la misma moneda. Esto es precisamente lo que hay que cambiar y para cambiarlo hay que emprender una educación política costarricense. El político medra de la clientela electoral el ciudadano medra del favor oficial. Este es el círculo vicioso $(1977,38)$.

Rodrigo Carazo veía en el Estado paternalista no solamente un nocivo sistema que imbuye a los ciudadanos en una zona confortable, sino también identificó la utilización de esta forma como un mecanismo clientelar, que achaca al político tradicional para poder aferrarse al poder mediante concesiones y prebendas.

La especialización en el tema de vivienda le llevó a ser el primer Gerente General del Instituto Nacional de Vivienda y Urbanismo (INVU) en 1954, ente creado, de acuerdo con Rovira Mas "para continuar el programa de viviendas populares iniciado por los gobiernos progresistas de la década de los cuarenta" $(2000,75)$. En sus cinco años al frente del Instituto, se empeñó para que se cumpliera con la obligación estatal de destinar un $3 \%$ del presupuesto para el financiamiento de los programas de vivienda $(1989,74)$, lo cual es evidencia de su creencia en un Estado social, el cual se reserva funciones que el mercado no puede, no debe o no está interesado en dar.

Asimismo, Rodrigo Carazo afirmó que el Estado al que aspiraba cuando se presentó como candidato de la Coalición Unidad, en 1977, era un:

Estado como instrumento y gestor del Bien Común (...)

Debe promover el bienestar general, la justicia social y la

superación moral y espiritual de los ciudadanos y la

comunidad nacional para lo cual tiene la responsabilidad

de dirigir, controlar y regular globalmente todo el proceso

social $(1989,200)$. 
En este aspecto, Carazo como líder de su coalición de partidos fue igualmente explícito, de hecho, bajo el subtítulo "La generalización del bienestar" $(1989,201)$ afirmó lo que consideraba las tareas del Estado era que éste debía ser:

Instrumento y gestor del bien común no interventor opresivo o abusivo; garantizar la libertad de todos los ciudadanos y no solo los que ya tienen privilegios exclusivos, para que contribuyan al logro del bienestar general, a la armonización de los intereses, a la superación moral (...) un Estado es responsable de dirigir, controlar y regular globalmente todo el proceso social.

Rodrigo Carazo hizo varias referencias a la regulación del mercado y las relaciones económicas por parte del Estado; pero, a diferencia de algunas interpretaciones sobre esta posición, la referencia que establece no es igualable a una negación de la empresa privada, sino que efectivamente creía en la armonización de ambos sectores. Así afirmó en 1978:

Mi gobierno estimulará a todas las ramas de la producción y a todos aquellos hombres de trabajo, a los empresarios, a todos aquellos capaces de crear riqueza y ocupación, con el fin de que la empresa privada y la libre iniciativa de los ciudadanos encuentren un campo fértil para promover la justicia social $(1978,12)$.

Sobre lo anterior, cabe resaltar dos aspectos sobresalientes: por una parte, no es de menor cuantía recordar la composición heterogénea, pero con una marcada tendencia liberal, de los partidos que integraron la Coalición Unidad; la bibliografía dedicada a este aspecto tiende a demostrar cómo esta unión se debió más al hecho de conformar una oposición contra el dominante PLN, que a una verdadera unión con una base ideológica fuerte y coherente. Esto se evidencia en la oscilación entre un Estado gestor con fuertes características sociales -posición que había mostrado Carazo- y un Estado que tienda más a ser el facilitador de las condiciones para el desarrollo de la iniciativa privada.

Aunque esto no plantea una contradicción necesariamente, en la praxis se evidenció con posiciones contrapuestas acerca de temas claves, mayormente económicos; la influencia de sectores como la Asociación Nacional de Fomento Económico (ANFE) (Rivera 1982, Rovira 1987 y 
Sánchez 2004) y la renuncia de funcionarios clave debido a cuestiones tanto coyunturales como de más largo plazo, fueron evidencia de ello.

Además, es menester señalar que, a pesar de cualquier otra aseveración político-económica, Rodrigo Carazo reafirmó permanentemente el concepto de la justicia social que, aunado a la propugnación del Bien Común, siempre advirtió al Estado como el garante último de ello; es decir, no se piensa en el mercado como el que cumpliría dicha función. Esto, como se verá más adelante, implicaba realmente un Estado fuerte y defensor de la institucionalidad como esa garantía de equidad. Sobre esto, véase lo dicho el día de la toma de posesión en mayo de 1978:

El Estado debe ser instrumento subsidiario para lograr el Bien Común, principio que deberá ser elevado a norma constitucional. Creo en un Estado al servicio del hombre y no éste al servicio de aquél $(1978,18)$.

A pesar de la primera impresión del término "subsidiario", y de acuerdo con la evidencia general analizada, Rodrigo Carazo no alude a un Estado subsidiario en tanto el que reorienta la gestión gubernamental a realizar acciones destinadas meramente a salvaguardar los derechos de propiedad, supervisar los intercambios mercantiles y comerciales así como vigilar la aplicación de las leyes (Huertas 2005, 135); es decir, un Estado que actúe solamente en los espacios en los que no interese actuar a los actores privados, lo cual podría interpretarse como la acepción negativa. La subsidiariedad a la que se refiere Carazo remite a una acción estatal garante de ese Bienestar Común y de justicia social en sectores sociales en desventaja.

La maduración del pensamiento de Rodrigo Carazo, al respecto del Estado, se vio expuesta en la dura coyuntura en la cual se desarrolló su gobierno durante el periodo 1978-1982. Por un lado, afirmó la responsabilidad del Estado ante la población $y$, por otro, agregó un componente a las características de esta organización social y que de ninguna forma redundante: una reapreciación del Estado como ente soberano y autónomo en sus decisiones.

Diversas fuentes secundarias, así como lo escrito por Rodrigo Carazo, coinciden en varios puntos señalados alrededor de dicha coyuntura: la presión constante, que vivían los países como Costa Rica desde los entes financieros externos, para alinearse a políticas restrictivas guiadas por principios de un naciente neoliberalismo económico como condición para efectuar transferencias que ayudaran a paliar las consecuencias de la crisis petrolera de la década de los años 1970.

Recuérdese que en el marco de Guerra Fría, Estados Unidos radicalizaba su política intervencionista en Latinoamérica para evitar cualquier subordinación de carácter socialista estimulada por la Unión Soviética y sus socios y el 
carácter crítico del deterioro de los términos de intercambio de países altamente dependientes que significaría el riesgo de una sumisión ante los entes financieros internacionales. Esta situación es resumida por Carazo así: "La política exterior de una nación como la costarricense tenía que considerar de manera fundamental la situación económica que golpeaba a las naciones pobres, a la vez que la situación se sordera que distinguía a las naciones económicamente fuertes". (1989, 363).

Como puede inferirse, los hechos de la época se tornaron altamente complejos y la relación de poderes de las cúpulas internas se acentuó en un momento determinado hasta alcanzar una agudización en diversos ámbitos de la organización social del país. Ante esto, se muestran signos importantes del Estado según Rodrigo Carazo.

Carlos Abarca (1995) apunta que el intervencionismo de Estado con signos democráticos exigía entre 1978 y 1982 una nueva alianza social para impulsar un proyecto de capitalismo dependiente con actitudes patrióticas ante la estrategia del capital financiero. Ello significaba un reto para la administración Carazo Odio y el camino sobre el cual se debe desarrollar el Estado en una época crucial de cambio.

Véase lo apuntado por Carazo a propósito de la relación político-económica del momento:

A las políticas de presión por la conquista de nuestros mercados para sus productos agropecuarios, se ha sumado la que pretende establecer una división internacional del trabajo que deja para nuestros países aquello que se produce industrialmente con mano de obra barata, producción por la que compiten bárbaramente los pueblos pobres, en tanto a los países industrializados se les ceden nuestros mercados de productos industriales mediante planes de ajuste estructural que nos llevarán a importar todo los sofisticado y caro y a pagar los servicios a precios cada día más altos. Los impulsores de este nuevo enfoque de dominio lo son el Banco Mundial (BM) y el Fondo Monetario Internacional (FMI) $(1989,369)$.

Lo anterior subraya, especialmente, la relación de desigualdad y menciona un actor crucial en el devenir posterior de los acontecimientos, el FMI, en tanto un acreedor que responde a intereses internacionales muy específicos en función de la implantación de un nuevo modelo a escala mundial. 
Así, este nuevo modelo propondría la mutación de los Estados de acuerdo con los nacientes principios fundamentales del proceso político-ideológico, que se consolidaría en las décadas siguientes, el neoliberalismo. Precisamente, Hidalgo (2004 113-115) sintetiza dos de estos principios que interesan particularmente para el presente artículo:

- El libre mercado: El mejor mecanismo que existe para asignar eficientemente los recursos escasos entre usos alternativos es el mercado, siempre que no se encuentre intervenido. Ninguna organización, por sofisticada que sea, incluido el Estado, puede sustituir la voluntad colectiva de los individuos que se manifiesta en el mercado.

- El estado mínimo: Cuanto más grande el Estado, más débil, más corrupto y menos eficaz es, pero esto no quiere decir que este no deba existir; por el contrario, el Estado ha de ser fuerte, pero pequeño, encargado de hacer cumplir las leyes y de prestar los servicios que le son inherentes, como el de la justicia y el orden público.

El planteamiento de reformulación del Estado es claro y los ejes fundamentales del proceso de liberalización económica planteados, ya desde la época, son muy conocidos y esto significó, entre otras cuestiones, la puesta en riesgo de los Estados benefactores y sociales de derecho y muchas de las funciones e inversiones como el gestor e interventor en aspectos claves de la organización social y el Bien Común al que hace mención Rodrigo Carazo. Este proceso paulatino, a nivel mundial, marcó un punto de maduración del pensamiento acerca del Estado, determinado indudablemente por el contexto.

La coyuntura de crisis mundial de la época fue definitoria para el desarrollo de los eventos; al respecto, Hidalgo $(2004,72)$ vuelve a apuntar:

La Administración Carazo se encontró con un contexto internacional muy adverso; el segundo shock petrolero de 1978, la elevación de los tipos de interés internacionales y la revalorización del dólar, la caída de la demanda de los productos tradicionales de exportación debido a la crisis internacional, la caída de la demanda interna del MCCA [Mercado Común Centroamericano] de productos industriales, el estallido de la violencia en la región centroamericana y, como consecuencia de ello, la fuga masiva de capitales y la caída de la inversión. 
4. Para un desarrollo más amplio sobre las políticas de estabilización exigidas por el FMl y las razones que derivaron en el incumplimiento de estas por parte del gobierno de Rodrigo Carazo, véase: Rivera, Eugenio. (1982). Fondo Monetario Internacional y Costa Rica. San Pedro: DEI, y Vargas, Luis P. (editor). (2007). Crisis económica y Ajuste Estructural. San José: EUNED.
Esta difícil situación de Costa Rica y las limitadas opciones planteadas por el sistema imperante, le llevó a negociar préstamos con el FMI para manejar la situación económica con profundas repercusiones sociales de la crisis y del modelo de sustitución de importaciones que derivó en una crisis fiscal. Así lo desarrolla de forma muy detallada Eugenio Rivera en El Fondo Monetario Internacional y Costa Rica (1982) y otros; el gobierno de Rodrigo Carazo negoció esos préstamos a cambio de cumplir con ciertas condiciones, todas ellas impuestas y no negociables.

Entre las principales políticas de estabilización exigidas por el Fondo remitían a restricción de gastos, aumento de diversas cargas impositivas, límites al endeudamiento del sector público y austeridad en muchas inversiones (Rivera 1982 y Carazo 1989). Pero, bajo las directrices de Rodrigo Carazo, el país no cumplió con muchos de esos compromisos adquiridos con el FMI (Rivera 1982 y Hidalgo 2004) pues, a criterio del presidente, el costo social era muy alto y el Estado no debía ignorar esas consecuencias. ${ }^{4}$ Soberanía y autonomía imperaban en sus decisiones.

El proceso negociador con el FMI, tras dos intentos fallidos, llevó a un encuentro entre el presidente Carazo Odio y un representante de dicho ente, en 1981, que evidenció el componente supra citado de la soberanía como elemento fundamental del Estado.

En dicho encuentro se pretendía negociar otra opción de transferencia por parte del Fondo con el fin de reducir los efectos de la crisis; de acuerdo con Carazo (citado por Castillo 2002, 55), el representante del FMI expresó:

Señor Presidente: lo que su gobierno debe hacer es
cerrar hospitales o algunos servicios que en ellos se
prestan; también debe cerrar colegios de enseñanza
media y enseñanza primaria y pre-escolar; cerrar
servicios de nutrición infantil, en fin, ajustarse a las
recomendaciones de mi representado el FMI.

Asimismo, Carazo (1989 y Castillo 2005) aseguró que el FMI sugirió una reorientación de la producción para consumo interno al mercado exterior casi en su totalidad. Sobre esto, Rodrigo Carazo comentó:

Mi gobierno consideró inaceptables las condiciones que exigía el Fondo Monetario Internacional en perjuicio de la gente pobre y además estimó que, por el mero hecho de proponer los "ajustes" que a su juicio deberíamos hacer se estaba violentando el respeto que una institución 
internacional debe guardar a una nación independiente $(1989,391)$.

"Entre comer y pagar la deuda externa, no hay alternativa" -dijo Carazo posteriormente. Esta reunión derivó en que, basado en que el FMI excedía -con irrespeto- por mucho sus funciones en detrimento de un Estado soberano, el presidente Carazo solicitó la salida inmediata de la misión del Fondo establecida en Costa Rica y declaró la moratoria de la deuda externa con todas las complejas consecuencias que esto significó. Sobre este momento, en 1989, Rodrigo Carazo escribió:

$$
\begin{aligned}
& \text { Sí aceptábamos las "sugerencias", se nos dijo, el país } \\
& \text { recibiría una ayuda en divisas que le permitiría hacerle } \\
& \text { frente a las obligaciones financieras con la banca } \\
& \text { internacional; nuestra respuesta fue firme y determinante: } \\
& \text { rechazábamos aquella "ayuda" ofrecida, no podíamos } \\
& \text { someter al país a las privaciones que los organismos } \\
& \text { internacionales pedían, ya que ello significaba la pérdida } \\
& \text { total de nuestra soberanía y el riesgo de que una } \\
& \text { población independiente y libre protestara por los abusos } \\
& \text { a los que se nos quería someter (1989, 392). }
\end{aligned}
$$

Cabe recordar los dos aspectos sugeridos previamente: por una parte, una evidente consolidación de su creencia en un Estado fuerte en lo social, de carácter benefactor con funciones interventoras en el ámbito económico más allá del papel subsidiario frente a las fuerzas del mercado como el virtual ordenador de la economía; es decir, se plantea claramente como oposición a un Estado liberal.

En un segundo aspecto, el atributo de la soberanía como una condición necesaria, mínima e inviolable del Estado, se consolida con el pensamiento de Rodrigo Carazo. De acuerdo a las definiciones clásicas del concepto, el poder soberano frente al territorio de la institución política estatal se da por hecho, pero en Carazo cobra una vitalidad nueva y se refuerza precisamente debido a la coyuntura; tal cual sucede con muchas concepciones -siempre cambiantes y adaptadas según el momento y las circunstancias- el rescate de la soberanía última del Estado frente a las fuerzas exógenas, que recobran igualmente una fuerza impresionante en la coyuntura de cambio de modelo con las primeras revueltas económico-políticas hacia el neoliberalismo en el momento de la administración Carazo Odio, es de muchas formas inédita. 
Rodrigo Carazo replantea la potencialidad de la soberanía del Estado -finalmente la soberanía de un país- y le ubica como una condición importante y de acatamiento obligatorio para quienes detentan el poder. Resalta, de nuevo aquí, la determinación de la coyuntura. Según Carazo:

Los países ricos nos sometían a toda clase de bloqueos económicos y financieros, no solamente por medio de los entes financieros internacionales sino también de sus gobiernos, en especial el de los Estados Unidos que ligaba los problemas económicos de Costa Rica a las posiciones por nosotros asumidas en materia de política exterior y soberanía $(1989,392)$.

La extensa bibliografía dedicada a la soberanía en tanto su revaloración en la sociedad costarricense en particular, y la sociedad latinoamericana, en general, por parte de Rodrigo Carazo, corroboran y respaldan esta propuesta. De hecho, Abarca $(1995,43)$ afirma que desde el origen del movimiento político gestionado por Carazo, para acceder a la presidencia, se caracterizaba fuertemente por retomar y reforzar un concepto global de soberanía popular como principio nacional, base de las demás acciones de gobierno a lo interno y externo.

Otro hecho concreto reconoce lo planteado acerca de la relectura caracista de la soberanía estatal por la trascendencia, pero a la vez por la invisibilización del hecho particular: un banco extranjero acreedor de Costa Rica presentó una demanda contra el Banco Nacional de Costa Rica ante la Corte de Apelaciones del Estado de New York debido a los perjuicios por la declaración de la moratoria de la deuda por parte del gobierno de Rodrigo Carazo (Carazo 1989, Asamblea Legislativa 2001, Castillo 2002). Según un libro de Alejandro Olmos citado por Carazo $(1989,2001)$ y Castillo (2005):

La Corte del Estado de New York, en un meduloso fallo resolvió que la conducta del Gobierno de Costa Rica era concordante con la política y la legislación de los Estados, y que aun cuando la decisión se refería a una actividad comercial, Costa Rica 'había procedido como país soberano la intentar impedir un desastre fiscal para la Nación'.

El hecho de que este fallo fuese ocultado en Costa Rica, como se sugiere más arriba, implica por sí mismo el peso que Carazo otorgó al principio de 
soberanía del Estado ante acciones y omisiones de entes exógenos. Precisamente, Rivera relaciona el hecho de la siguiente forma:

(...) la curiosa circunstancia de que los bancos internacionales hayan reaccionado encubriendo el hecho de que Costa Rica había dejado de pagar la deuda externa. La Nación informaba que los nueve bancos privados más importantes pedirían a las restantes instituciones acreedoras de Costa Rica que no realizaran acciones judiciales contra Costa Rica por el no pago de la deuda $(1982,156)$.

\section{La empresa pública: neurálgica e identitaria}

Rodrigo Carazo fue intenso en su reflexión acerca de la empresa pública. Se mostró crecientemente activo sobre el tema a medida que el sistema económico a partir de la década de 1980, que propugnaba la apertura de mercado en detrimento de las funciones estatales -y en contra de la empresa pública-, iba consolidándose. De acuerdo con Chávez y Torres, a partir de esta época y sobre todo a partir de la década de 1990 "durante el apogeo del Consenso de Washington (...) la visión hegemónica establecía que las entidades de propiedad estatal eran intrínsecamente ineficientes y debían ser privatizadas" $(2013,14)$.

En términos generales, la empresa pública, como lo plantea Cipriano Mauro (1987), implica dos dimensiones: lo público y lo empresario.

Este autor explica que el factor público alude fundamentalmente a la posesión (una propiedad de, al menos, 50 \% de acuerdo con Mauro 1987, y Chávez y Torres 2013) y control del ente por parte de autoridades públicas, lo cual significa que la labor de dirección esté a cargo de los designados por parte de las autoridades públicas. Asimismo, dentro de este apartado, el elemento del propósito público de la empresa es fundamental, lo cual implica grosso modo que debe responder al interés público.

Podrá inferirse, entonces, que este tipo de intervencionismo es un paso más del Estado regulador para convertirse en un Estado que también produce bienes y servicios con un afán de lucro -pero esto puede diferir del tipo de objetivo de la empresa privada- y pasa a ser sujeto de derecho privado. Pero, la particularidad resalta en que la empresa pública puede llegar a cumplir, como bien lo señalan Chávez y Torres (2013), tres roles diferentes: social, económico y de internacionalización. Se destaca que el respaldo estatal para sus empresas llega a ser crucial en los casos de crisis económicas, se 
subsidia la producción y se salvaguarda el servicio para todos los estratos sociales, a diferencia en muchos casos de la empresa privada.

Desde esta concepción, corresponde interpretar el pensamiento de Rodrigo Carazo acerca de la presencia, el desarrollo y el papel de la empresa pública en Costa Rica.

Como lo menciona Cortés $(2013,117)$ : "Costa Rica ha construido a lo largo de la historia una matriz de instituciones y empresas públicas que ha configurado una forma muy particular de intervención del Estado así como un estilo de desarrollo específico", es decir, las condiciones históricas del país han proveído un marco determinado que ha influido directamente en la consolidación de ese sector público diferenciado de la gran mayoría de casos en América Latina al punto de resistir los cambios exigidos por los modelos impuestos desde la década de 1980, en función de la consolidación del neoliberalismo.

El modelo costarricense del periodo 1950-1980 se construyó sobre una base ideológica estructurada en intervención estatal con una fuerte influencia en la distribución de la riqueza, lo cual llevaría a que, a partir del gobierno de 1982, se evidencie fuertemente la respuesta del costarricense ante el cambio, aspecto resaltado constantemente por Rodrigo Carazo.

Ese desarrollo de la empresa pública ha tenido una influencia en el imaginario y la cultura del costarricense, lo cual ha significado que un amplio sector de la sociedad mantenga un concepto positivo y de identificación con esta. Ello se traduce, cuando aplica, a una alta fidelidad y defensa en determinados momentos.

El origen socialdemócrata de Rodrigo Carazo se mantuvo estable, en términos generales, a lo largo de su vida en su reflexión y acción política; de allí que su percepción acerca del Estado de Bienestar fue moldeando un pensamiento constante acerca del grado de intervención del Estado en diversos aspectos de la vida y la organización de la sociedad costarricense hasta mostrarse activamente sobre el tema desde el primer lustro de la década de 1990.

De acuerdo con el estudio de Bodenheimer sobre el inicio de la socialdemocracia en Costa Rica, el PLN como su primer impulsor reafirmaba un Estado que "planifique y regule los sectores básicos de la economía, así como varias dependencias autónomas del Estado o empresas públicas (en seguros, vivienda, turismo, electricidad, etc.), aunque se deje un gran margen de libertad para la empresa privada". (1984, 44-45). Como es sabido, dos de las decisiones cruciales que tomó la Junta Fundadora de la Segunda República fue la nacionalización de la banca y la creación del Instituto Costarricense de Electricidad (ICE), ambos casos en función de un proyecto de desarrollo nacional reconociendo igualmente la existencia de capas sociales históricamente olvidadas.

Sobre esto, Rodrigo Carazo aseguró que la generación a la cual perteneció veía "la nacionalización bancaria como instrumento popular de crédito" (1989, 
54); es decir, reconociendo el aporte -y la necesidad- de la banca estatal en función de una repartición equitativa de la riqueza, así como ser gestor del desarrollo. Igualmente, Carazo recuerda que, en el periodo que fungió como diputado nacional por el PLN (1966-1970), se mostró como un fuerte opositor a la desnacionalización bancaria, incluso contra miembros de su misma bancada.

Ese modelo de desarrollo, que marcó la evolución de la sociedad costarricense en prácticamente tres cuartas partes del siglo pasado, ocupó mucha de la reflexión de Rodrigo Carazo, quien respaldó en particular la empresa pública como un factor innegociable e insustituible que, entre otros aspectos, implica la prestación de servicios para una mejora en la calidad de vida, un elemento crucial en la redistribución de la riqueza, y, sobre todo, patrimonio nacional que, como tal, no se debía negociar.

De acuerdo con Rodrigo Carazo, el Estado en general y la empresa pública en particular son garantes -y deben serlo- de la solidaridad y la equidad a lo interno de las sociedades y cumplen una función más allá del lucro en un contexto en el cual "los resultados obtenidos en el planeta por las políticas neoliberales han lanzado a muchos a sentirse preocupados" (2000, 11). Precisamente, este contexto influyó decisivamente tanto el concepto de la función como la presencia de la empresa pública en su pensamiento.

En este sentido, Rodrigo Carazo siempre fue enfático. Incluso, en su obra constantemente aludía a que su gobierno fue el último bastión de defensa estatal ante la avalancha neoliberal, que se consolidaría desde mediados de la década de 1980.

Desprendido de su análisis de coyuntura, Rodrigo Carazo concluiría que las relaciones de desigualdad entre los países son la base de la relación de dependencia de Estados como Costa Rica y esto finalmente se alinea en las condiciones propicias para la imposición de un modelo basado en la explotación extrema que requería de un Estado mínimo fundamentado en privatizaciones, al punto de verse en entredicho la dignidad y la soberanía del país.

Como parte de sus planteamientos de campaña, Rodrigo Carazo afirmó posteriormente:

Insistimos en que la sociedad está en el deber de desarrollar un sentimiento generalizado -y ya probado- en cuanto a que la empresa está llamada a cumplir una función social mediante su contribución al progreso económico de la comunidad y la dignificación del trabajo mediante beneficios para todos los que aportan el esfuerzo laboral en la creación de la riqueza, y que debe 
tener como inspiración fundamental la generalización del bienestar $(1989,201)$.

Su gobierno inició en un momento de crisis debido al aumento de los precios de petróleo, caída abrupta de los precios del café y la idea de un modelo que había agotado sus posibilidades. Esto significó la ventana de oportunidad que la corriente neoliberal en auge se plantara con más firmeza y el sector económicamente poderoso del país, con varios de sus representantes en el seno del mismo gobierno central, presionara por cambios profundos en la misma estructura económica del país, influidos en gran medida por las ideas del binomio Thatcher-Reagan, quienes constituyeron una mancuerna de presión internacional para que, con base en los entes económicos internacionales, se estimularan políticas neoliberales en los países establecidos bajo su sombra de influencia.

La imposición de tales presiones llevó al inicio de una ola privatizadora y de desmantelamiento del Estado en todos los países de Latinoamérica, pues, como lo menciona Rodrigo Carazo, se instituyó una tesis en la cual el Estado era visto como algo innecesario y estorboso $(2000,21)$ y ello tendría un efecto en la constitución misma de la identidad de cada país latinoamericano en función de un proyecto con un origen ajeno.

Sobre ello, Carazo acotó

Nos repitieron los neoliberales, hasta convencer a muchos, que el modelo costarricense se había agotado y que por ello nos debíamos someter al mandato foráneo que exige que los pueblos pequeños seamos dependientes y pobres y que todos ellos vivan en la periferia, olvidando lo que somos y aspirando a ser lo que nunca seremos, en una carrera sin fin de absorción y de pérdida de identidad (1989).

En consonancia con lo anterior, Rodrigo Carazo atribuía los problemas de Costa Rica a una dependencia psicológica que se relacionaba con una supeditación de los valores morales a los intereses económicos; todo esto con una complacencia y una complicidad de sectores de interés a lo interno del sistema político y del sector comercial.

Un aspecto sobresaliente en la coyuntura de su gobierno fue, desde luego, el denominado Estado empresario en la figura específica de la Corporación para el Desarrollo S.A. (CODESA). Este ente significó el momento máximo de la penetración del Estado en actividades lucrativas con la conformación de varias empresas que pretendían "impulsar el apalancamiento financiero y técnico desde el Estado" (Cortés 2013, 124). Este proceso inició en 1972, 
pero se mostró operacional en 1976 durante la administración de Daniel Oduber.

No interesa pormenorizar los detalles de la inacabada consolidación de CODESA, pero sí es relevante aportar que la entidad significaba una gran deuda estatal en la coyuntura de las elecciones de 1978.

Es interesante observar cómo, a pesar de representar un componente crítico del aparato estatal, con fuertes enemigos que consideraban necesario su cierre, Rodrigo Carazo creía que, con una restructuración CODESA, se podría aportar para el desarrollo del país. Precisamente, en su programa de gobierno se expresaba que las empresas estatales debían servir como ese instrumento de desarrollo y esto se daría

Reestructurando CODESA a fin de convertirla en un ente que promueva realmente el desarrollo nacional mediante: la revisión exhaustiva de sus operaciones, la participación en proyectos auténticamente nacionales, el apoyo a actividades del sector privado que sean técnica y económicamente factibles, la participación del mayor número de costarricenses en la propiedad de sus acciones $(1977,40)$.

Lo anterior significaría, en la práctica, una reducción de la corporación a un conjunto de empresas públicas sólidas, vitales y de carácter estratégico tales como RECOPE y Fertilizantes de Centroamérica S.A. (FERTICA); es decir, una necesidad de reducción de este aparato derivado de una mala gestión por parte de la administración Oduber al no reportar las inversiones a la Oficina de Planificación Nacional (OFIPLAN) y perder en estas millones de dólares (Carazo 1982 y 1989). Finalmente, dicha reforma no se llevó a cabo por otras decisiones tomadas en la Asamblea Legislativa, que derivaron a un mediano plazo en el cierre definitivo de la corporación.

La reflexión en Carazo es clara sobre la venta de activos estatales por cuanto "después de la entrega, no hay regreso, ni defensa, ni democracia que valga, ya que los electos a cargos públicos tienen que limitarse a pedir que les suenen la campana para saber... 'que ya viene el lobo'" (Carazo, 2000, 16).

La fuerte ofensiva neoliberal fue impuesta en Latinoamérica con implicaciones políticas y sociales muy altas. Como bien lo apunta Ramón Grosfoguel: "Durante este periodo, los Estados (hegemónicos) hicieron un esfuerzo geopolítico dirigido a destruir los movimientos populares y democráticos exitosos en la periferia". (2003, 154). Esto implicó que toda oposición se viera minimizada y, por el contrario, los sectores sociales afines a la incursión del nuevo modelo se vieran apoyados por los centros 
democrático-capitalistas para presionar a lo interno e ir encaminando el sistema en dicha dirección.

En dicho contexto, "las políticas neoliberales de libre comercio fueron impuestas sin mucha dificultad ni resistencia por las organizaciones disciplinarias de capital global (Fondo Monetario Internacional, Banco Mundial, etc.)" (Grosfoguel 2003, 154). En este último punto, sobre todo, Costa Rica se vio fuertemente influenciada.

La imposición del FMI, a la cual Rodrigo Carazo se opuso en su gobierno, encontró un terreno más fértil en la administración de Luis Alberto Monge (1982-1986), facilitado por el descontento popular incitado contra Rodrigo Carazo. Se trató del chivo expiatorio de las consecuencias de la crisis mundial.

Este momento significó el comienzo de una contraofensiva neoliberal interna, que llevó a la pugna política y social alrededor de temas importantes que enfrentarían en Costa Rica la preferencia de un Estado reducido frente a la conservación del Estado de Bienestar, lo cual, evidentemente, significó una repercusión en la empresa pública.

Los Programas de Ajuste Estructural (PAE) iniciaron su incursión en Costa Rica a partir del primer lustro de la década de 1980, como un estímulo y condicionante para la transición hacia el modelo neoliberal. Lo anterior conllevó la imposición de ciertas pautas dirigidas a una liberalización de la economía, tal como menciona Álvaro Montero (1990, 204): "el programa se impone sin ninguna consideración con las causas reales que originan los desequilibrios ni con las consecuencias políticas y sociales que surgen".

Es este contexto el que tiene una fuerte influencia sobre el desarrollo del pensamiento de Rodrigo Carazo y termina de madurar su posición acerca del reforzamiento de la empresa pública en particular y del Estado social de derecho y bienestar, en general, al verlas como un bastión que debe ser consolidado -por ende, entre otros aspectos, no privatizado- en función de la resistencia de las imposiciones exógenas de las cuales estaba convencido sobre su finalidad de dominación.

Sobre los PAE, Rodrigo Carazo escribió:

Bien se sabe que los PAE son programas inspirados en una orientación capitalista internacional (...). Los PAE, sea cual fuere el país al que se apliquen, se distinguen por:

- Exigen la privatización indiscriminada de las empresas públicas. 
- Piden reducir los presupuestos públicos con destino a programas sociales.

- Prohíben las subvenciones a la producción local y en los programas sociales $(1995 \mathrm{a}, 11 \mathrm{~A}) .^{5}$

5. El artículo original propone 9 puntos en total; para efectos de esta investigación, se tomaron

Asimismo, Carazo escribiría que "los planes de ajuste estructural exigen, entre varias condiciones, el que el país se abra a un solo mercado mundial en beneficio de los exportadores poderosos. Ese mercado mundial reclama la apertura de inversión extranjera". (1995d, 5).

De acuerdo con su criterio, los PAE no promovían ni gestionaban una distribución más equitativa de la riqueza y, por el contrario, servían como un propulsor para que las empresas transnacionales absorbieran toda empresa pública y se consolidaran como la fuerza única en el mercado y ello derive, a todas luces, en una entrega progresiva de la institucionalidad.

Así, estos proyectos y directrices finalmente respondieron a intereses supranacionales y entes especializados que buscaban, mediante el condicionamiento y la coacción financiera, la imposición del modelo de interés.

A partir de este momento, la relación entre neoliberalismo, apertura o privatización se torna como un conjunto de temas de abordaje permanente en la opinión y el pensamiento de Rodrigo Carazo al establecer, de hecho, varias relaciones causales y apoyándose constantemente en la evolución de los acontecimientos nacionales e internacionales con repercusión nacional, lo cual se convierte a la postre en la reflexión más rica y profunda no publicada con la formalidad de un libro sino en diversos foros públicos, tribunas de opinión, revistas científicas, entre otras.

Rodrigo Carazo percibió el avance del modelo neoliberal como el principal enemigo del Estado y sus aliados internos como el mayor peligro. Consideraba que debía existir, en función de un verdadero desarrollo, un equilibro entre las fuerzas del mercado y un Estado sólido. Ese desarrollo implicaba la consolidación de una empresa pública fuerte integrante de una institucionalidad madura; por ende, el hecho de afectar esta institucionalidad lleva a la facilitación de las condiciones para la imposición de un modelo que produce desigualdad y crisis. En otras palabras: "es propio recordar que los problemas que conocemos como crisis económicas por lo general son producto del desmantelamiento al que fueron sometidas las instituciones estatales a lo ancho y largo del planeta" (Carazo 2000, 20).

En una de sus reflexiones al respecto, Carazo se muestra muy claro y conciso: "De lo que era Estado dirigente, se ha pasado a Estado dirigido, propiedad de algunos" (2000, 21). Ello, particularmente, fue denunciado progresiva y sostenidamente por Carazo a lo largo de muchos años. 
Una vez que los tecnócratas neoliberales ganaron espacio en el ámbito político costarricense y con la aprobación del PAE I (1985) y el PAE II (1989), el tema de discusión de la reforma del Estado tomó preponderancia en la agenda política nacional como una herramienta estratégica que, utilizando la bandera de la "modernización", tendería a seguir consolidando el marco del modelo neoliberal con la institucionalización, inclusive de una comisión para el efecto en la coyuntura de un tercer PAE en 1995.

En este contexto surgió con más fuerza la tesis de la venta de activos públicos en concordancia con el modelo y un año después, durante la administración del liberacionista José María Figueres, que surge con más fuerza -y presión desde diversos sectores- la venta del activo más significativo y emblemático del Estado costarricense: el ICE, que cumple un rol estratégico de electricidad y telecomunicaciones.

En esta coyuntura, "los actores proclives al proyecto neoliberal tomaron como caballo de batalla el elevado monto de la deuda interno e instrumentaron una de las campañas más agresivas con el propósito de avanzar hacia distintos esquemas de privatización" (Castillo 2002, 125).

A partir de aquí, una pugna que se reavivó alrededor del futuro del ICE en el marco de un modelo que no era, en primera instancia, compatible con la existencia de monopolios estatales, y en mucho menos de los que fuesen exitosos. La defensa del Instituto se amplió a significar la defensa de un modelo de Estado, que históricamente había sido el responsable de una mayor equidad en la distribución del ingreso así como motor para el ascenso social. Esto conllevó a la consolidación de alianzas de diversos actores sociales individuales y colectivos alrededor de esa defensa. Surge así, presidido por Rodrigo Carazo, el Consejo para la Defensa de la Institucionalidad (CDI).

De acuerdo con la Carta orgánica de la CDI, en sus artículos 1 y 2, este ente:

- Es una organización política que aglutina organizaciones y personas comprometidas en la lucha por el Programa de la Asamblea del Pueblo y los documentos ideológicos aprobados por ella.

- Es una organización pluralista y sustenta su actividad en los principios y valores de justicia y solidaridad social, democracia participativa, civilidad y tolerancia, extraídos del quehacer histórico de los costarricenses.

Una vez creada y formalizada la CDI, Rodrigo Carazo, quien tuvo un papel fundamental tanto en su conformación como en su desarrollo, ejerció un papel activo en la difusión de sus ideas acerca del Estado y la empresa pública costarricense en un contexto de presión ideológica y política contra estos, en especial el ICE.

Para ese momento, el discurso de Rodrigo Carazo acerca de la privatización es bastante claro y extendido; sobre ello, en 1995, Carazo escribió: 
Tanto se ha popularizado la privatización, que mucha gente cree que ella es buena en sí misma... Los inversionistas potenciales desean la privatización para hacerse de buenos negocios; ellos insisten en lo que ahora se llama 'reducir el tamaño del Estado'; ponen a toda su presión en la venta de activos de propiedad pública, y le hacen creer a muchos que si se vende todo lo que es propiedad del Estado, nadie tendrá que pagar impuestos (1995, 17A).

Tomar participación activa y dirigente en la CDI definió con fuerza la dirección ideológica de Rodrigo Carazo en torno al asunto de la empresa pública en Costa Rica y su función dentro de proceso forzado de transición entre modelos con base en un fuerte componente de privatización.

Su presencia en diversos foros impulsó su legitimidad para desarrollar una defensa coherente acerca de la vigencia de la institucionalidad frente a la ola privatizadora y su papel en un Estado de bienestar que, según Carazo, no es un modelo caduco o anacrónico, según se intenta calificar desde sectores interesados en su modificación estructural; al respecto, expresó que "el proceso de privatización se fundamenta en una campaña de desprestigio de las empresas públicas; se dice que dan pérdida, que producen mal, que son burocráticas" (1993, 19a).

Así, el papel de la empresa pública en el desarrollo del país y sobre todo la responsabilidad de estas en la disminución de los déficits del aparato estatal son, de acuerdo con Carazo, dos de los aportes más reconocidos de estos entes autónomos o los descentralizados. Este convencimiento le imposibilita comprender las iniciativas endógenas tendientes a la privatización de esos activos públicos, al tiempo que desconfiaba de la influencia extranjera que iba en este mismo sentido:

Resulta increíble, al menos para mí, que quieran vender 'a troche y moche' la vaca que hace posible que el sector público tenga leche. Las presiones foráneas por la privatización eso sí, siempre me ha parecido más inspirado en el deseo de que unos pocos puedan apoderarse de estos países, que en el de ayudarnos. ¿Quién podría creer que los organismos internacionales nos exigen vender 'malos negocios'?... Solo los ingenuos $(1993,19 a)$. 
En particular, Rodrigo Carazo se avocó, desde la palestra personal y la de la CDI, a demostrar mediante datos concretos que la venta de los activos públicos no conlleva a la reducción del déficit estatal y más bien sí tiene un efecto en la calidad de vida de los habitantes y del servicio, tanto como la elevación de los costos. Al respecto de este tema, Rodrigo Carazo escribió en 1999:

Todos los países se convierten en promotores incondicionales de las empresas transnacionales: se desregula, se privatizan las economías, se abre la competencia global que hace sucumbir naciones enteras ante el influjo financiero y el dominio económico de unas pocas centenas de grandes empresas que se adueñan del planeta y empresas que conforme crecen se van uniendo entre ellas $(1999,11)$.

Un argumento relevante del discurso caracista es la particularidad de un modelo institucional costarricense diferenciado como el resultado de una historia política propia que es, asimismo, la razón que influye en la existencia de un vigoroso movimiento social en el momento que el colectivo considera que esas instituciones se ven amenazadas; de acuerdo con Rodrigo Carazo, Costa Rica "transformó el modelo liberal tradicional latinoamericano hacia uno propio, singular y positivo, que nos puso a transitar por el sendero de la esperanza; capaz de avanzar; de tratar de superar problemas; de ser dueños de nuestro destino" (Castillo, 28).

Analizando sus palabras, el modelo costarricense es ciertamente alternativo. Se caracteriza, asimismo, por mantenerse alejado de los extremos ideológicos y tiene una influencia constante en la cultura política del costarricense. Por tanto, "se resiste a desaparecer"; así, Rodrigo Carazo consideró que:

Se construyó una estructura ideológica basada en un modelo de desarrollo con una fuerte injerencia estatal en la distribución de la riqueza y que marcaría en mucho la respuesta de los costarricenses frente a los cambios que se vienen proponiendo al modelo de desarrollo a partir de $1982(1989,128)$.

Asimismo, Rodrigo Carazo, el día que recibió el premio Rodrigo Facio Brenes por parte de la Universidad de Costa Rica en 1998, expresó que: 
El modelo costarricense (...) hizo posible -hasta que algunos lo empezaron a debilitar- que el país viviera la confianza en sí mismo, con fe en sus instituciones. Algunos, pensando solamente en sus intereses, han tratado de debilitarlo, diciendo que está agotado; con la ayuda de presiones foráneas, tratan de imponernos otro modelo, que en muchos países se evidencia obsoleto por lo absurdo e injusto: el modelo neoliberal (1998).

A pesar de la línea de pensamiento desde la élite política dominante y la acción avocada a la consolidación de ese modelo hegemónico, Carazo siempre se convenció de que el efecto que el modelo neoliberal debía tener en las empresas públicas, lejos de privatizarlas, era de fortalecerles; de hecho, consideraba que la fortaleza de la institucionalidad pública había entorpecido los intereses del sector neoliberal y de ponerle en manos privadas. Esto tenía un efecto directo en la paz social.

Dicho efecto es planteado por Carazo así: las instituciones públicas son garantes de la justicia social mediante su labor en diversos ámbitos dedicados a reducir brecha y brindar servicios accesibles. Esta justicia es el elemento principal para una consolidación de la paz social; por lo tanto, una modificación en la naturaleza de este ámbito estatal tendería a una correspondencia en la sociedad, que significaría una perturbación con derivación en movimientos expresos de reproche.

Una última coyuntura que evidenció y consolidó las proposiciones de Rodrigo Carazo acerca de la empresa pública en tanto solidez, defensa y reacción de la ciudadanía costarricense fue el Referéndum sobre el Tratado de Libre Comercio entre Estados Unidos, Centroamérica y República Dominicana (en adelante TLC) en 2007.

Este proceso basaba su significancia en, al menos, tres aspectos puntuales:

- Era el primer referéndum que se realizaba en Costa Rica.

- Significó un punto culminante del proceso de auge neoliberal iniciado desde la década de 1980 en el país. Contó con el apoyo de la mayoría del capital costarricense.

- Su discusión significó, en un plano más amplio, una discusión sobre el modelo de desarrollo que guiaría a Costa Rica en los siguientes años; es decir, el TLC representaba no solamente un acuerdo comercial sino una apuesta político-económica con consecuencias sociales.

Como parte de los acuerdos dentro del Tratado, se encontraba la apertura de monopolios estatales estratégicos como los seguros y las 
telecomunicaciones, en especial la telefonía celular. Ello implicaría cambios estructurales relevantes en la conformación de la institucionalidad costarricense a la par de otra gama compleja de implicaciones en diversos ámbitos de la organización social y económica, que quedaron evidenciados en el proceso de discusión nacional de este acuerdo. Sobre esta situación y de forma temprana, viendo los procesos de otros países latinoamericanos, en 1993, Carazo escribió:

Estimo que no podemos quedarnos aislados. Considero bueno e importante el matrimonio con otros pueblos y esto puede culminar con la incorporación de Costa Rica al TLC, pero empezando por un casamiento sólido con los vecinos centroamericanos, que nos permita negociar con los grandes en condiciones razonables. No creo eso sí, que, con tal de estar juntos debamos aceptar el amancebamiento como forma de vida; si así actuamos, ninguna ventaja será garantizada por derecho alguno, y la dignidad de nuestra nación quedaría igual, otra vez, a como fue mancillada al convertirnos en área de entrega al Norte, allá por 1985, a cambio de dinero (Carazo 1993a, 23a).

Lo anterior se escribió en función del recién aprobado TLC entre Estados Unidos y México, pero plantea dos cuestiones resaltables de la interpretación histórica de Rodrigo Carazo sobre el tema:

a) Reconocer los acuerdos comerciales como parte de un ineludible proceso de globalización e integración.

Rodrigo Carazo percibía la globalización diferenciada del globalismo. Este último concepto involucra una sociedad mundial solidaria en la cual la pobreza sería un asunto de todos con base en el respeto de los Derechos Humanos (Carazo 2001, 16a). Para él, la globalización se estableció como un conjunto de reglas fundadas sobre la extraterritorialización de las grandes empresas, con una función primaria de acumulación de capital abstraída del elemento humano y que polarizó el mundo entre pobres y ricos, al tiempo que "los gobernantes se transforman en gobernadores que representan intereses extraños y no de sus pueblos" (Carazo 2001, 16a).

Pero, a pesar de ello, no puede eludirse su primacía en las relaciones mundiales y deben asumirse las reglas para tratar de cambiarlas. 
b) En torno a esas reglas, los países en desventaja deben, en el mejor de casos, unirse pero sobre todo, deben exigir y luchar por condiciones justas en los términos de intercambio.

Sobre este punto versó una gran parte del discurso de Rodrigo Carazo y, de hecho, su oposición al TLC -a desarrollar en las próximas líneas- se concentró, entre lo principal, en una fuerte crítica de los términos de intercambio negociados en los cuales consideró que no había una verdadera equidad ni competitividad real dadas las obvias diferencias entre los países firmantes, al tiempo de su efecto negativo en la institucionalidad pública.

Al respecto, Carazo afirmaba que, como consecuencia de la globalización, se da la desaparición de las empresas pequeñas y estatales "que proporcionan trabajo a lo largo y ancho del planeta y se habla de libre comercio practicado para las empresas sin patria" (Carazo 2001, 16a).

Desde muy temprano en el proceso, Rodrigo Carazo formó parte de lo que se denominó el Movimiento del NO, que argumentaba en contra de la aprobación del TLC. Este fue "un movimiento descentralizado constituido por una gran diversidad de actores políticos y sociales y se sostuvo con trabajo voluntario" (Raventós 2008, 19). Este movimiento se organizó territorialmente en los denominados Comités Patrióticos, coordinados desde un espacio articulado llamado Comisión Nacional de Enlace, cuya fundación se dio "en la casa de habitación y con el patrocinio del Expresidente de la República, Rodrigo Carazo Odio. Luchador incansable contra el TLC y el libre comercio hasta su muerte acaecida en el mes de diciembre de 2009" (Comisión de Enlace 2014).

Los objetivos de la Comisión fueron los siguientes:

a) Derrotar el TLC definiendo posiciones, una estrategia y una agenda común para el movimiento social.

b) Forjar un frente unificado de lucha.

c) Construir y movilizar una gran fuerza social, mediante la cual se potenciara al máximo la lucha contra el TLC y se lograra el mayor éxito de la lucha.

Durante su alocución en el lanzamiento de la campaña del NO, en junio de 2007, Rodrigo Carazo expresó: "Si por dinero se ha vendido el honor; se ha entregado la patria, debemos todos cerrar el puño para evitar la impunidad y abrir bien los ojos para que nada quede oculto; ¡no al TLC!"

Tal como ya se apuntó, el proceso de consulta sobre el TLC se convirtió en cierta forma en un proceso de respaldo o negación del modelo de desarrollo propuesto por los sectores sociales hegemónicos que favorecían un fortalecimiento de la forma neoliberal de desarrollo y esto tendría un efecto en la conformación de la empresa pública, tal como se concibió desde las décadas previas.

Este acuerdo se enmarca, entonces, en un proceso en el cual, de acuerdo con Carazo, "los países pobres fueron obligados a quitar fronteras a las 
mercancías e inversiones extranjeras, a las cuales se les abrió también la puerta para que compraran los activos institucionales propiedad de los pueblos" (Castillo 2002, 36).

La influencia que el TLC tendría sobre Costa Rica traspasaba por mucho, de acuerdo con Rodrigo Carazo, el ámbito comercial para tener un efecto directo en la convivencia social producto de la injerencia en temas álgidos como la agricultura y el modelo establecido en relación con la empresa pública, por lo cual debía ser rechazado en las urnas y no asumir como verdaderos e inapelables varios de los postulados del movimiento del sí en tanto una condena y efectos sociales y económicos negativos para el desarrollo del país.

Su discurso sobre el tema demostró su conocimiento sobre este tipo de acuerdos y sus repercusiones:

Es bueno aclarar que el TLC lo incluye todo: seguros comerciales, generación eléctrica, comunicaciones, servicios públicos, propiedad intelectual, todo lo que se pueda controlar con el dinero y el poder económico. El TLC prácticamente obliga a la privatización de aquellas actividades y empresas que han hecho de Costa Rica un país diferente a otros en cuanto a salud, educación y eliminación del ejército y en todo aquello que lo ha convertido en un país de paz, gracias a la justicia social cuya superación ha motivado, por muchas décadas, a nuestros gobiernos (Voltairenet 2014).

El ajustado resultado a favor del Sí (51 \% - 48 \%) reflejó la polarización en juego, así como otros factores que no interesa desarrollar aquí, pero que confirmaban lo apuntado por Carazo acerca del peso que la empresa pública tiene en el ojo de la discusión nacional como un factor diferenciador y la pasión que despierta en sus defensores, aspecto que se demostró de hecho en el transcurso del proceso con una gran vitalidad de los movimientos sociales.

El elemento de "vender la patria", usual en la retórica de Rodrigo Carazo, cuando se hace presente la privatización o apertura de empresas públicas, se vio reflejado en su discurso del 8 de octubre, al día siguiente del proceso del referéndum:

Ya sabemos bien quiénes la aman y respetan [a la Patria]

y cuáles son los que realmente desean aprovechar en su 
exclusivo beneficio lo que es Costa Rica. (...) La gesta

valiente de los costarricenses que se expresaron de una manera contundente contra el TLC "vende patria" a pesar de los enormes obstáculos que les pusieron enfrente (Carazo 2007).

Se observa la relación estrecha entre lo público y el elemento emocional que permanentemente Rodrigo Carazo establecía al tiempo de colocar una etiqueta muy dura sobre los actores que tuvieran interés en modificar estructuralmente el status quo de este ámbito en una función de acciones y resultados guiados por los principios neoliberales.

\section{Apuntes finales}

El estudio del pensamiento y la obra de actores políticos claves en el devenir de un país resultan útiles para poder comprender la historia, la cultura política y los hechos que le dan forma a una sociedad. Costa Rica posee un acervo destacado de pensamiento, no únicamente de políticos destacables como Rodrigo Carazo, sino de muchos otros intelectuales que han aportado de manera impecable al estudio del ser costarricense.

Rodrigo Carazo es resultado de un contexto preguerra civil que le llevó a consolidar un entendimiento valioso del Estado costarricense y de lo que debía cambiarse. Su relación con figuras de la talla de Rodrigo Facio, Joaquín García Monge o José Figueres, influyeron decisivamente en su percepción de la política, el Estado y la empresa pública costarricense. Particularmente, el nacimiento político de Rodrigo Carazo, junto con la creación del Partido Liberación Nacional (PLN), le permitió comprender una forma naciente y enérgica de organización del sistema político, al tiempo que comprendió cómo los intereses creados tienen un efecto en las personas que integran el ámbito político y que pueden redefinir sus posiciones originales. Esto le permitió interpretar los procesos internos del partido que, finalmente, decidirían en su dimisión, porque no comulgaban con la idea original del aparato estatal, que se había concebido en la Costa Rica de la posguerra.

Lo anterior lo llevaría a buscar, mediante los mecanismos formales, el acceso al poder y, de acuerdo a sus declaraciones, dignificar la política y comprender que la función pública no es una palestra por sí misma, sino que mantiene un objetivo claro de trabajar en pro del Bien Común y, cualquier forma de apartarse de este objetivo, es inaceptable. Esto le llevó a ser crítico acérrimo de muchos políticos nacionales e internacionales.

Su ejercicio de la presidencia, en una etapa crucial, basado en una fuerte crisis externa, redefinió la aplicación del concepto de soberanía para un país con las características de Costa Rica. Se atrevió a desafiar paradigmas 
históricamente incuestionables y esto llevó a que fuese criticado y convertido en el blanco de campañas políticas posteriores. Su conflicto con el FMI marcó un momento indeleble en la historia política nacional, de lo cual se habla hasta la actualidad. Pero, lo interesante consiste en que no solo se habla de ello únicamente en términos históricos, sino también se vuelve a esos momentos para revisar una forma de actuar alternativa frente a las presiones externas, que buscan doblegar las instituciones domésticas a través de actuaciones basadas en poderío económico. Esto se reflejó, también, en la animadversión frente al Tratado de Libre Comercio.

Un Estado fuerte y una empresa pública eficaz son, en función de su papel frente a las presiones extranjeras tanto de países como de entes económicos y financieros internacionales así como frente a las empresas transnacionales, sinónimo de dignidad y soberanía para Rodrigo Carazo; el Estado es el primer bastión para dignificar y buscar términos de intercambio más justos entre las potencias y los países emergentes para los cuales la unión es un elemento crucial en un contexto de globalización económica, que tiene como efecto primordial un debilitamiento de las naciones en beneficio de grandes centros económicos con fuerza política, que dicta las reglas a la comunidad internacional según su criterio de interés.

Para Carazo, la empresa pública es un componente crucial de un Estado social de derecho, pues significa un aporte al Bien Común y en Costa Rica es parte del acervo cultural, pues el apego de los ciudadanos es muy particular, lo cual es una razón suficiente para entender que la historia reciente del país va de la mano de sus instituciones.

Rodrigo Carazo consideró que las instituciones públicas son las principales garantes de la justicia social; que, cada una, desde diversas ramas y especializaciones tienen por fin último la reducción de la brecha social, a partir de proveer servicios accesibles y dignos para todos los integrantes de la sociedad. El elemento crucial de esta búsqueda de equidad y justicia incide en la consecución de la paz social.

\section{Bibliografía}

Abarca, Carlos. 1995. Rodrigo Carazo y la utopía de la dignidad 1970-1983. Heredia: EUNA.

Asamblea Legislativa. (2001). Acta de la sesión ordinaria No. 12 de la Comisión Mixta que estudia los problemas sobre la deuda pública sus causas y consecuencias. Expediente 14112.

Benavides, Enrique. 1977. Nuestro Pensamiento Político. San José: Editorial Costa Rica. 
Bodenheimer, Susanne. 1984. La ideología socialdemócrata en Costa Rica. San José: EDUCA.

Carazo, Rodrigo. 1968. Administración de vivienda. Caracas: Fondo Editorial Común.

Carazo, Rodrigo. 1978. Mensaje de toma de posesión.

Carazo, Rodrigo. 1989. Carazo Tiempo y Marcha. San José: EUNED.

Carazo, Rodrigo. (1993, 12 de febrero). «¿Privatizar lo que sí produce?» La República 19a.

Carazo, Rodrigo. (1993a, 22 de diciembre). «El TLC debe ser conocido». La República 23a.

Carazo, Rodrigo. (1995, 28 de junio). «Vender por vender» La República 17a.

Carazo, Rodrigo. (1995a,15 de julio). «Los PAE». La República 11a.

Carazo, Rodrigo. (1995d, 28 de julio). «¿Privatizar el ICE?». Esta Semana 5.

Carazo, Rodrigo. 1998. Palabras de Rodrigo Carazo en la entrega del premio Rodrigo Facio Brenes de la Universidad de Costa Rica.

Carazo, Rodrigo. (1999, 10 de diciembre). "Desarrollo... Fin de siglo». La Prensa Libre 11.

Carazo, Rodrigo. 2000. La Tercera Vía ¿es posible en nuestra América? Cartago: LUR.

Carazo, Rodrigo. (2001, 25 de agosto). «Fundamentalismo globalizador». La Nación 16a.

Carazo, Rodrigo. 2007. Palabras de Rodrigo Carazo sobre el resultado del Referendum del 7 de octubre de 2007.

Carazo, Rodrigo. Ver TLC: Ricos poderosos y pobres débiles. Consultado el 15 de noviembre de $2014 . \quad$ En: http://www.voltairenet.org/article121494.html

Castillo, Mario. 2002. Rodrigo Carazo: con la dignidad en las venas. Cartago: Ediciones El Castillo.

Chávez, Daniel y Torres, Sebastián. 2013. La reinvención del Estado. Empresas públicas y desarrollo en Uruguay, América Latina y el mundo. Montevideo: TNI.

Coalición Unidad. 1977. Bases del programa de gobierno. Imprenta LIL. 
Comisión de Enlace. Ver ¿Quiénes somos? Consultado el 15 de noviembre de 2014. En: http://comisiondeenlace.co.cr/nosotros

Cortés, Alberto. 2013. «El Estado, empresas públicas y desarrollo en Costa Rica: Una mirada de larga duración (1850-2013)». En La reinvención del Estado. Empresas públicas y desarrollo en Uruguay, América Latina y el mundo, editado por Daniel Chávez \& Sebastián Torres, 117-131. Montevideo: TNI.

Dahl, Robert. 1968. Análisis sociológico de la política. Barcelona: Fontanella. Grosfoguel, Ramón. 2003. «Cambios conceptuales desde la perspectiva de sistema-mundo. Del cepalismo al neoliberalismo». Nueva Sociedad, 183: $151-166$

Hidalgo, Antonio. 2004. Costa Rica en evolución. San José: Editorial de la Universidad de Costa Rica.

Huertas, María. 2005. «El neoliberalismo y la conformación del Estado subsidiario». Política y cultura, 24: 121-150.

Mauro, Cipriano. 1987. Análisis de la política pública en el desarrollo de la industria naval paraestatal. México: INAP.

Montero, Álvaro. 1990. «El desarrollo imposible: Algunas reflexiones sobre el Ajuste Estructural». En Crisis económica y Ajuste Estructural, editado Luis Paulino Vargas, 173-258. San José: EUNED.

Mora, Arnoldo. 1993. Historia del pensamiento costarricense. San José: EUNED.

Raventós, Ciska. 2008. «Blance del referendo sobre el TLC en Costa Rica a la luz de la teoría de la democracia»". Revista de Ciencias Sociales, 21(3): 13-29.

Rivera, Eugenio. 1982. Fondo Monetario Internacional y Costa Rica 19781982. San Pedro: DEI.

Rodríguez, Eugenio. 1995. Voces del 43. San José: Editorial Universidad de Costa Rica.

Rodríguez, José Daniel. 2014. Informe final de investigación: El Estado y la Empresa pública en el pensamiento de Rodrigo Carazo Odio. Escuela de Ciencias Políticas - CIEP. UCR. 
Rovira, Jorge. 1987. Costa Rica en los años '80. San José: Porvenir.

Rovira, Jorge. 2000. Estado y política económica en Costa Rica 1948-1970. San José: Editorial Universidad de Costa Rica.

Sánchez, Rafael. 2004. Estado de Bienestar, crisis económica y ajuste estructural en Costa Rica. San José: EUNED.

[Sin pelos en la lengua No al TLC]. (2007, 5 de julio). Lanzamiento campaña No TLC 23/6/07 Parte 4. [Archivo de vídeo]. Recuperado de

https://www.youtube.com/watch?v=MY34qWZ-a-o

Vargas Solís, Luis Paulino. (editor). 2007. Crisis económica y Ajuste Estructural. San José: EUNED.

Weber, Max. 2012. El político y el científico. Madrid: Alianza Editorial. 